\title{
Research on the Coverage of Different Newspapers Under Major Disasters
}

\section{- Take Henan Daily, Henan Business Daily and Dahe Daily's Coverage of the July 20 Henan Rainstorm as an Example}

\author{
Yuhan Wang* \\ School of New Media Art, Xi'an Polytechnic University, Xi'an, 710048, China \\ Corresponding Author's Email: 1075937831@qq.com
}

\begin{abstract}
The significant economic losses and casualties caused by Henan rainstorm on July 20, 2021 has been closely followed by domestic media. This paper has analyzed 181 news reports concerning the devastating floods from July 21 to July 31 by Henan Daily, Dahe Daily and Henan Business Daily using the method of content analysis and found that they all focus on such issues as human, material and financial aids, relief measures, post-disaster improvement of public facilities and the impact of the disaster, thus finding the focus and form of the three mainstream newspapers in Henan when covering major disasters.
\end{abstract}

Keywords: Disaster news, Henan Daily, Henan Business Daily, Dahe Daily

\section{INTRODUCTION}

Since July 17 , there has been a significant precipitation in Henan and its capital city Zhengzhou has witnessed $258.1 \mathrm{~mm}$ rainfall in 24 hours, which is the first extraordinary rainstorm in its history, significantly exceeding its historical record. As of 12:00 on August 2, 302 people were killed and 50 people missing in Henan province and Zhengzhou alone lost 53.2 billion yuan as a direct result of the disaster.[10]

Previous studies on disaster news focused mostly on the reporting framework and humanistic care. For example, by comparing the coverage of the Tianjin explosion by People's Daily and Tianjin Daily, Chen Mei suggests that different types of newspapers adopt different types of reporting frameworks: People's Daily highlights the frameworks of leadership and accountability while Tianjin Daily demonstrates the dynamic framework of the accident.[1] By analyzing reports of the Wenchuan earthquake, Ma Meng proposed that the strategies for constructing collective memory mainly include the orientation of news reports, the focus during the report, the strengthening of the memorial rituals and the carrying-forward of memorial symbols.[2]This flood is so special that there appeared many new reporting characteristics deserving attention, which leads to the topic of this research: What issues did local media in Henan focus on in terms of this flood? What was the focus?

\section{SAMPLE SELECTION}

Henan rainstorm on July 20 is so disastrous that lots of media have covered it. To reflect different media perspectives, three mainstream newspapers in Henan Province have been selected for this study: Dahe Daily, Henan Daily and Henan Business Daily. Henan Daily, founded on June 1, 1949 as the organ of the CPC Henan Provincial Committee, is the most official and guiding newspaper in Henan Province, belonging to Henan Daily Newspaper Group. As an instructive, service-oriented and readable newspaper that tops Henan, it has become a must-read one for party and government cadres and leaders of enterprises to make decisions and give guidance as well as an important medium for people from all walks of life and successful people to learn the latest news, exchange economic information and pass their spare time, enjoying an incomparable reputation and influence among communication media. Dahe Daily, sponsored by Henan Daily Newspaper Group, is a comprehensive urban-life newspaper aimed at caring about people's livelihood, advocating fashion, close to 
life and serving the masses. With its colorful content, unique style and refreshing market development strategy, it has produced a shocking social impact, featuring a large amount of information, strong readability and high circulation. Henan Business Daily, sponsored by Henan Daily Newspaper Group, was founded in 1983. The purpose of the newspaper is to promote business and influence people in Henan with businessmen as its core users and civil servants and women as the key users.
From July 21 to July 31, there were 74 articles in Dahe Daily, 56 articles in Henan Daily and 51 articles in Henan Business Daily about the rainstorm in Henan, so the total number of sample was 181 . The topics covered by the three newspapers concluded after sorting out their content are shown in the following table:

Table1. Statistics of topics reported by three newspapers

\begin{tabular}{|c|c|c|c|c|c|c|}
\hline & Assistance & Rescue & Relief measures & $\begin{array}{c}\text { The scale of the } \\
\text { disaster }\end{array}$ & $\begin{array}{c}\text { Facility } \\
\text { improvement }\end{array}$ & Others \\
\hline Henan Daily & 19 & 3 & 13 & 4 & 14 & 3 \\
\hline Dahe Daily & 24 & 11 & 3 & 18 & 15 & 5 \\
\hline $\begin{array}{c}\text { Henan Business } \\
\text { Daily }\end{array}$ & 13 & 9 & 2 & 15 & 8 & 4 \\
\hline
\end{tabular}

According to the topics reported, the text of Henan rainstorm reports are classified into six categories: human, material and financial assistance; rescue; relief measures; the scale of the disaster; post-disaster facility improvement and others. The specific data shows that Henan Daily and Dahe Daily cover assistance-related news most, accounting for $33.9 \%$ and $32.4 \%$ of the total respectively. $29.4 \%$ of the reports by Henan Business Daily covers the impact of the disaster, which is the highest among the three newspapers. Henan Daily reports rescue measures most with the percentage of $23.2 \%$, which is much higher than the $4 \%$ of Dahe Daily and $3.9 \%$ of Henan Business Daily. This has accurately conveyed the voice of the Party and government and its determination to formulate relief measures.

\section{THE ANALYSIS OF REPORTING TOPICS}

\subsection{Assistance-related News}

The 19 pieces of news in Henan Daily focus on government rescue with relatively few detailed and indepth reports while striving to ensure the authority of each news. On the front page of July 29, it reported on the settlement of the affected people, highlighting the government's ability of governance and emergency response so as to stabilize social emotion, and on page 5 of July 29, the 7 people reported were all the members of the Communist Party of China helping people in the front line of the flood. Dahe Daily focused on assistance with 24 articles on human, material and financial support, more than the other two. They emphasized the amount of donations. For example, it reported that various charitable organizations and the Red Cross in Henan received more than 4.5 billion yuan on AI-02 of July 26and flood-fighting materials worth over 3 billion on
AI-06 of July 27 and over 3 billion yuan, of which 2.788 billion yuan has been distributed. The fund raised by Henan Provincial Charity Federation has broken the record.[6]It is worth noting that in these three newspapers, only Dahe Daily covered that Hongxing Erke donated to Zhengzhou Charity Federation 2 million yuan and material worth 18 million yuan. Their reporters found there has been a sales surge when they visited Hongxing Erke stores, which is related to the news and hot topics online in the same period. Henan Business Daily had 13 related reports on specific donations or materials from major enterprises or individuals.

\subsection{News about the Impact of the Disaster}

4 reports in Henan Daily are about the impact of the disaster, accounting for only $7.1 \%$ of the total, which is the smallest. Most of the figures reported by the newspaper are government officials, party members leading in the efforts of flood control and disaster relief, with strong political orientation and guidance. Take it page 03 on July 21 as an example. When reporting deputy township chief Wang Peng guarding the Shanmen River Bridge in the Taihang Mountains in Xiuwu County, Jiaozuo City, it says "he standing there against a red Party Flag at the beginning of the bridge as the flood flow has dropped back from 70 cubic meters per second to 30 cubic meters per second."[2] The proportion of coverage on this by Dahe Daily and Henan Business Daily reported has exceeded 20\%. On Dahe Daily's page A04 of July 31, 292 forest fire commanders from Beijing, Huangshan, Wuhan, Nanchang, Changsha come to the aid of Zhengzhou, pumping out the stagnant water from 5 areas in 3 subways as deployed. As of 8:00 on the 30th, a total of 530,000 square meters of water has been drained, equivalent to two Zhengdong New District Ruyi Lake.[5] As the saying goes, when trouble occurs at one spot, help comes from all quarters. The report of hotels providing 
free bathing has also reflected the characteristics of livelihood newspaper: emotions must be elevated and public opinion expressed after the facts. Only Henan Business Daily reported the exact number of deaths and direct economic losses by the rainstorm. For example, on its page A02 of July 22, the change of the average precipitation in the province was as accurate as "one hour later". It says that from 0:00 on the 20th to 0:00 on the $21 \mathrm{st}$, an extraordinary rainfall occurred in Zhengzhou area, with an average precipitation of $302 \mathrm{~mm}$ and the maximum precipitation of $696.9 \mathrm{~mm}$ in Jiangang, Erqi District and direct economic loss of over 540 million yuan, killing 25 people and making 7 missing.[7] The precipitation is accurate to one decimal point and clarifies the maximum precipitation point, reflecting the newspaper's strictness in and sensitivity to numbers.

\section{ANALYSIS OF THE CHARACTERISTICS OF THE REPORTS}

\subsection{The Appearance of Omnimedia}

In response to changes in the market environment, Henan Daily Newspaper Group has created a full range of media, expanding the number and scale of platforms to facilitate its transformation and development. This change is also reflected in the sample of this study. Dahe Daily's AI-03 page of July 27, Henan Daily's 03 page and Henan Business Daily's A03 page all reported an article entitled "Coming Back to Life from Despairs-The Documentary of the Big Transportation of the Affected by the Storm on July 207-20" by Zhang Xuewen, Ke Yang, Li Xiaomin, Xiong Zhuotian, Omnimedia reporters from Henan newspaper media. They gave a comprehensive coverage of the big transfer of the affected.[3] Although the pictures are different, their content are similar, which is divided into four stages: critical moment, full-range transfer, participation in the battle and regaining the light. It tells stories of orthopedic surgeon Ho Yingjie encountering a sudden power outage during surgery, Central War Zone Political Commissar Zhu Shengling commanding a major military-civilian coalition, ordinary people joining the rescue team and the 71 year-old Mr. Liu's transfer by helicopter. These great transfers were reported from the individual point of view, enabling readers to empathize with the words while highlighting the unity of the people.

\subsection{New Forms of Reports}

\subsubsection{Omnimedia Reports}

In the era of universal self-media, news dissemination has become simple and convenient. Major news sharing platforms have directly simplified the expression of audience.[8] Dahe Daily reported on AI-06 page of July 24 on firefighters sending text messages to encourage the trapped girl with a screenshot of the text message rather than the photos or videos shot by reporter at the scene. During the interview, the reporter learned that the firefighters lied to the girl in the text message communication, because this was the only way to make the girl feel the hope of life. At the same time, the firefighters told reporters that they'd better not since the girl doesn't want to be reported. At the end of the interview, they told the reporters to code the phone number in the text message so as not to make the girl feel hurt again if this is to be published in the newspaper. This kind of humanistic care is an essential part of disaster news yet not all journalists bear this in mind. The psychological state of the affected is also something that journalists urgently need to take into account in their interviews. Whether the journalist are empathetic with the affected and whether the affected would be hurt again shall be considered in reports. The main reason for the lack of humanistic care is journalists' misunderstanding of journalism and their simple and brutal way of interviewing.

\subsubsection{Live Streaming Rescue}

With the development of Internet technology, the connotation of live streaming has been expanded in a new way. The benefits of live streaming can be well exploited through network signals, thus reducing costs and speeding up the spread of information. The live-video ecological chain has also become more popular, giving people the freedom to choose from a wide range of platforms. With the massive transfer of traffic from PC to mobile, live streaming has gained universal popularity as a new means of social interaction and sharing.[9] It has also played an active role in the rescue work of the Henan flood disaster. Dahe Daily reported on the "radio action" initiated by Henan Video in which a female anchor broadcast live for 12 hours, reporting more than 300 effective help-seeking information for rescue workers inside and outside the province. The anchorwoman "rescue in tears" while helping rescue workers find at least 15 people through the rapid transmission of information via the network. The "radio action" to help rescue was launched under the coordination of all parties concerned. The staff of Henan Video kept discussing with that from Tik Tok and Headlines Today about broadcasting plans to the midnight, which demonstrates the determination of news media to be firm in their stance professional ethics of journalists.

\subsection{Coverage Disparities and Focus of Different Newspaper}

The above analysis shows that the three types of newspapers have different focuses. As a livelihood newspaper, Dahe Daily covers a wide range of topics; Henan Business Daily focuses on business and economic life; while Henan Daily is more party-oriented and almost all of its reports are slogan-like measures and 
condolences from leaders to the disaster areas with political characteristics, giving relatively few reports on casualties and timely people-benefit news due to the limited space. It pays more attention to hard news, yet the other two focus on livelihood news, reflecting the reporting characteristics of different types of newspapers.

In terms of language style, Dahe Newspaper better reflects the change of emotions, using a lot of adjectives such as "excited" and "anxious" to express strong emotions and vividly recreate the scene at that time. For example, it reported Yu Yifei, an intern doctor who knelt on the ground for six hours to help a dozen people in the subway on AI-10 of July 23. It focus on soft news, reporting on livelihood news with real events of ordinary people. As it directly quoted Yu Yifei's words in his Circle of Friends: "After all the cardiopulmonary resuscitation, I was too exhausted to stand up", the empathy of the report was strengthened. On the contrast, Henan Business Daily emphasized the commendation Yu Yifei received after saving several people on A05 page of July 23 rather than reproducing the event. This was not reported by Henan Daily.

\section{CONCLUSION}

As new media grow rapidly, traditional ones, instead of sticking to the traditional reporting framework of time, place, people and events, are looking for innovations and breakthroughs. "Live radio" and "SMS screenshots" are inevitable in the new era of ubiquitous self-media. Only by integrating themselves into new ones can paper media produce news in pleasant-to-all forms. Different media will have different focus when reporting on the same disaster. Specially, Henan Daily, as an official, guiding party newspaper, has to accurately convey the mainstream voice of the party and government. Dahe Daily, a livelihood newspaper, naturally cares about people's livelihood and serves the public. While Henan Business Daily is a business newspaper with its focus on business and economic life.

Reports on disasters should be more authentic, empathetic and quality-oriented in the era of all-media. With the springing up of self-media, how do conventional media survive and how to highlight the core value of humanistic care when reporting major disasters? Mainstream media should consider readers more, understand their needs so as to play its role in calling on people, guiding people and gaining confidence.

\section{REFERENCES}

[1] Chen Mei. Research on Major Disaster and Accident Reports of Central and Local Media from the Perspective of Frame Theory -- Taking People's Daily and Tianjin Daily's Report on Tianjin Explosion Accident on August 12 as an example [J]. Southeast Communication, 2016(7): 71-73.
[2] Chen Xuehua, Yao Guangqiang: The Party Flag Is as Red as Fire Against Wind and Rain, Reporters of Henan Daily, July 21, 2021, 3rd Edition.

[3] Han Lu. Development Strategy of All Media from the Perspective of Industrial Convergence -- A Case Study of Henan Daily Newspaper Group [J]. View on Publishing, 2018, No.320(14): 49-51.

[4] Ma Meng. Discourse Strategies of Collective Memory of Major Disaster Events in Mainstream Media -- Taking People's Daily's report on Wenchuan Earthquake as an example [J]. News Research Guide (3): 3.

[5] Shao Keqiang: They Have Discharged Two "Ruyi Lakes" from the Subway, Dahe Daily, July 31, 2021, A04.

[6] Shen Bin: This "Fad of Caring about Countrymen" Sets off a Wave of Solidarity and Shopping Enthusiasm, Dahe Daily, AI • 10, July 27, 2021.

[7] Sun Ke: 25 were Killed and 7 Missing after the Extreme Rainstorm, Chief reporter of Henan Business Daily, A02, July 22, 2021.

[8] Yin Xinruo. Analysis of the Impact of We-media News Communication on Traditional News Communication [J]. Media Forum, 201,4(13): 3536.

[9] Yuan Mengyue. Research on The Power of Communication $[\mathrm{J}]$. Research on Transmission Competence, 2019, 3(08):39.

[10] Zhu Peixian: 302 Dead, 50 Missing, Direct Economic Loss of 114.269 billion Yuan in Henan After Heavy Rainfall, Huashang News, CCTV News, Xinhua News Agency, People's Daily APP, August 2, 2021. 